\title{
Co-Pt (Cobalt-Platinum)
}

\section{H. Okamoto}

In [Massalski2], the $(\alpha \mathrm{Co})$ to $(\varepsilon \mathrm{Co})$ transition in the $\mathrm{Co}$ Pt phase diagram was uncertain due to a large hysteresis observed between the heating and cooling curves corresponding to this transition. Figure 1 shows the [Massalski2] phase diagram with the $(\alpha \mathrm{Co})$ to $(\varepsilon \mathrm{Co})$ transition modified according to [1999Zao], who assessed the Co-rich portion of the phase diagram by taking into account the heating and cooling kinetics.

\section{References}

1999Zao: J.C. Zhao: Z. Metallkd., 1999, vol. 90 (3), pp. 22332.

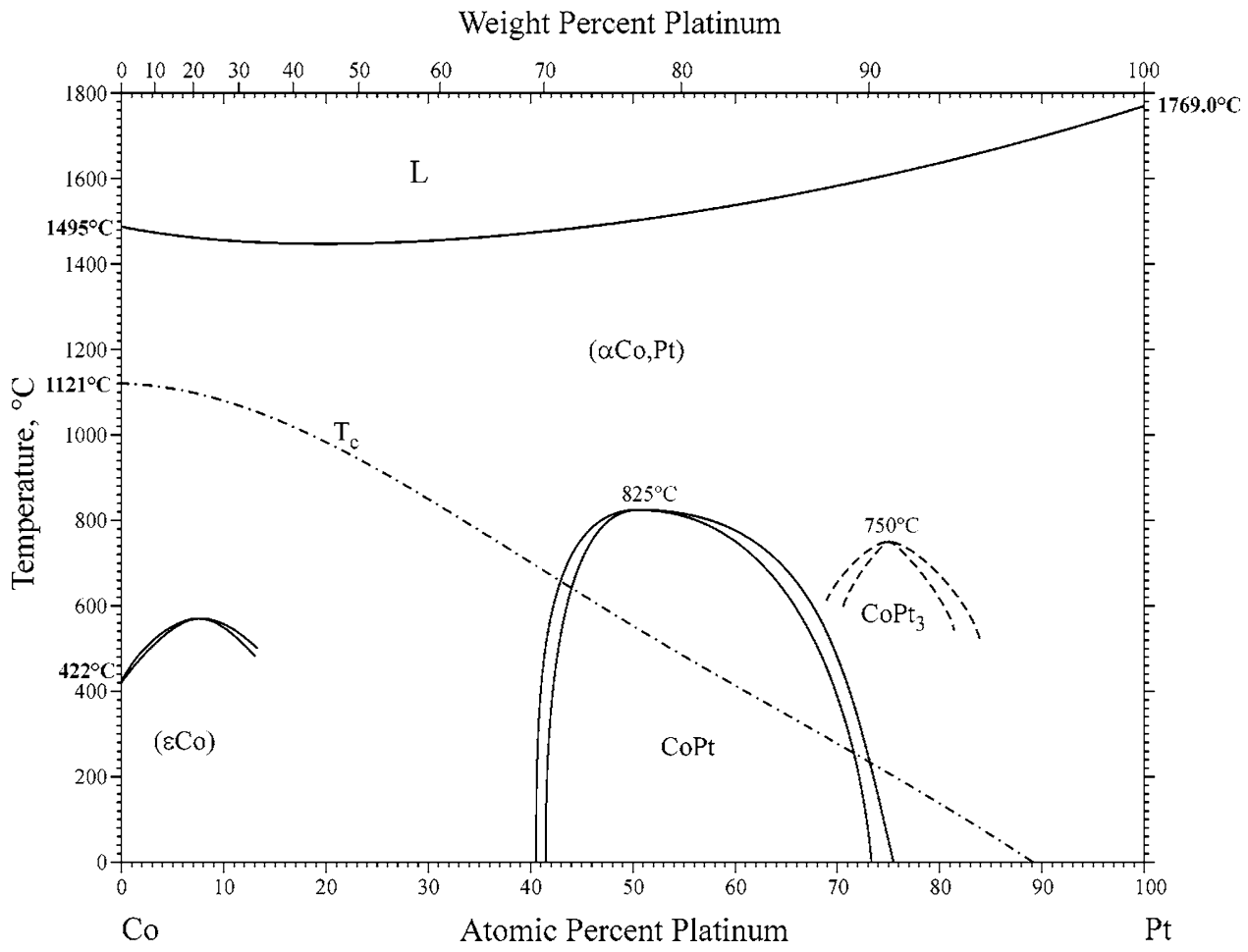

Fig. 1 Co-Pt phase diagram 